\title{
Australia-SH Antigen in Hepatitis Patients in London
}

\author{
Y. COSSART,* M.B., M.C.PATH. ; P. E. TAYLOR, $†$ B.SC., PH.D. ; J. VAHRMAN, $\ddagger$ M.B., M.R.C.P.ED., C.P.H. \\ A. J. ZUCKERMAN,§ M.D., M.C.PATH., DIP.BACT.
}

British Medical fournal, 1969, 3, 755-756

\begin{abstract}
$S^{\text {und }}$ ummary : Australia-SH antigen was found in 11 out of 27 sera (40\%) obtained from patients with acute viral hepatitis soon after their admission to hospital. Six out of 11 positive sera were collected within the first 12 days of illness; the remaining five were collected between the 13th and 30th days. The antigen was detected by immunodiffusion in agarose gel, five different indicator sera containing Australia-SH antibodies being used. The specificity of these sera was found to be very similar.

All of the patients' sera were examined independently by two separate laboratories. The results obtained by the laboratories were in close agreement, though the techniques varied in detail.
\end{abstract}

\section{Introduction}

The Australia-SH antigen has been recently described in sera collected from patients with acute hepatitis during the incubation period or early acute phase of the illness, and from 13 to $80 \%$ of the patients studied have been found to carry this antigen (Okochi and Murakami, 1968 ; Prince, 1968 ; Gocke and Kavey, 1969 ; London, Sutnick, and Blumberg, 1969 ; Levene and Blumberg, 1969).

In all those studies the antigen was demonstrated by the immunodiffusion technique in agar or agarose gel. The serum containing antibody was usually obtained from patients who had received many blood transfusions. It may be that in these patients repeated exposure to the hepatitis agent through receiving large quantities of blood may result in the production of a specific precipitating antibody. The antigen so detected has been referred to as the Australia antigen ( $\mathrm{Au}(1)$ ) (Blumberg, Sutnick, and London, 1968), the SH antigen (Prince, 1968), and the hepatitis antigen (Gocke and Kavey, 1969). The exact relationship between these named antigens has not yet been clearly established, but it is likely that they are either closely related or identical. Because the techniques used by the different groups of investigators have been similar, any variation in the results obtained is of interest, since it may indicate differences both in the specificity of the antisera used and in the aetiological agents encountered. Other factors, such as the time at which the specimens were collected and the sensitivity of the diffusion methods, might also have influenced the findings.

Direct comparison of the results obtained in two separate laboratories testing the same specimens could elucidate some of these problems. Samples of serum from patients with viral hepatitis, collected soon after admission to the Western Hospital, Fulham, were sent in duplicate to the London School of Hygiene and Tropical Medicine and to the Virus Reference Laboratory, Central Public Health Laboratory, Colindale, where they were examined under code for the presence of Australia$\mathrm{SH}$ antigen. The results obtained by each laboratory were later compared and correlated with the clinical histories of the patients.

\section{Materials and Methods}

\section{Clinical Specimens}

Blood samples were obtained soon after admission from 27 consecutive clinical cases of viral hepatitis at the Western Hospital in the first six months of 1969. The diagnosis of viral hepatitis was made on the basis of history, clinical picture, and laboratory findings. All of the patients were icteric. No attempt was made to classify the cases as either infectious or serum hepatitis. Clotted blood was taken soon after the patients' admission to hospital and sent by post to each laboratory. After separation the serum was stored frozen either at $-30^{\circ}$ or $-55^{\circ}$ C. until tested.

\section{Indicator-sera}

The sera containing Australia-SH antibody were of human origin. Two sera were used in both laboratories as follows: (a) anti-Au (1) (CO41177) obtained from Professor B. S. Blumberg, Philadelphia, and (b) anti-SH serum (Saunders $4 \times-$ concentrated) provided by Dr. A. M. Prince, New York. Two additional antisera were used at the School of Hygiene only. These were: (c) anti Au-SH (donor F), supplied as lyophilized plasma by Professor R. W. Collum, New Haven, and used 3xconcentrated, and $(d)$ serum MW from a patient with a refractory anaemia who had received more than 100 transfusions of packed red cells. The last-mentioned serum was provided by Dr. C. Cameron, of the East of Scotland Blood Transfusion Service, Royal Infirmary, Dundee, Scotland. At the Virus Reference Laboratory one further serum was used, (e) Patient L.B., obtained from a multiple-transfused haemophiliac and supplied by Dr. K. Dormandy, of the Haemophiliac Centre, Royal Free Hospital, London.

The following comparisons of the indicator-sera have been made. At the School of Hygiene all of the antisera used gave lines of identity when tested against a "reference" AustraliaSH antigen (Patient T.) supplied by Dr. R. W. McCollum. In the Virus Reference Laboratory the three sera used gave lines of identity when tested against a reference Australia antigen (CO45378) supplied by Dr. B. S. Blumberg. The sera were titrated in doubling dilutions against the same antigen. Anti-Au (1) and serum L.B. gave similar endpoints of $1 / 16$, but anti-SH could not be diluted beyond $1 / 2$. When testing patients' sera for the presence of antigen the detector sera were used undiluted except for donor $F$., which was used $3 \times$-concentrated, and Sanders which was $4 \times$-concentrated.

\section{Immunodiffusion Technique}

In each laboratory agarose gels were prepared by the method of Prince (1968). This agarose was dissolved in a buffer composed of $0.1 \mathrm{M}$ sodium chloride, $0.01 \mathrm{M}$ tris (hydroxymethyl) aminomethanol ( $p \mathrm{H} 7.6$ at $25^{\circ} \mathrm{C}$.), $0.001 \mathrm{M}$ ethylenediamine/ tetra acetic acid containing $1 \mathrm{mg}$. of protamine sulphate per $\mathrm{ml}$. At the School of Hygiene merthiolate was added to the gel to give a final concentration of $1 / 5,000$.

A similar pattern of six equivalent wells surrounding a centre well were used in both laboratories. At the School of Hygiene the tests were performed in $190-\mathrm{mm}$. Sterilin plastic Petri dishes with $2.5-\mathrm{mm}$. wells $4 \mathrm{~mm}$. apart and a gel volume of $15 \mathrm{ml}$.,

* Consultant Virologist, Virus Reference Laboratory, Colindale, London N.W.9.

† Research Associate, London School of Hygiene and Tropical Medicine, London W.C.1.

$¥$ Consultant in Infectious Diseases, Western Hospital, London S.W.6. $\$$ Reader in 'Virology, London School of Hygiene and Trapical Medicine, 
whereas in the Virus Reference Laboratory $1 \mathrm{ml}$. of gel on a standard microscope slide was used and the wells were $2 \mathrm{~mm}$. in diameter and $5 \mathrm{~mm}$. apart.

Gels were stored for at least 24 hours at $4^{\circ} \mathrm{C}$. before use. After the addition of the test sera they were kept in a moist chamber at room temperature and read daily for four days (Virus Reference Laboratory) and seven days (School of Hygiene).

\section{Results}

Details of the 27 patients examined for the presence of Australia-SH antigen are given in Table I. The patients had abnormal serum aspartate aminotransferase (S.G.O.T.) and raised total bilirubin levels in their serum. Sera obtained soon after admission to hospital from 11 of the 27 patients were found to contain the antigen. None of the convalescent sera were positive.

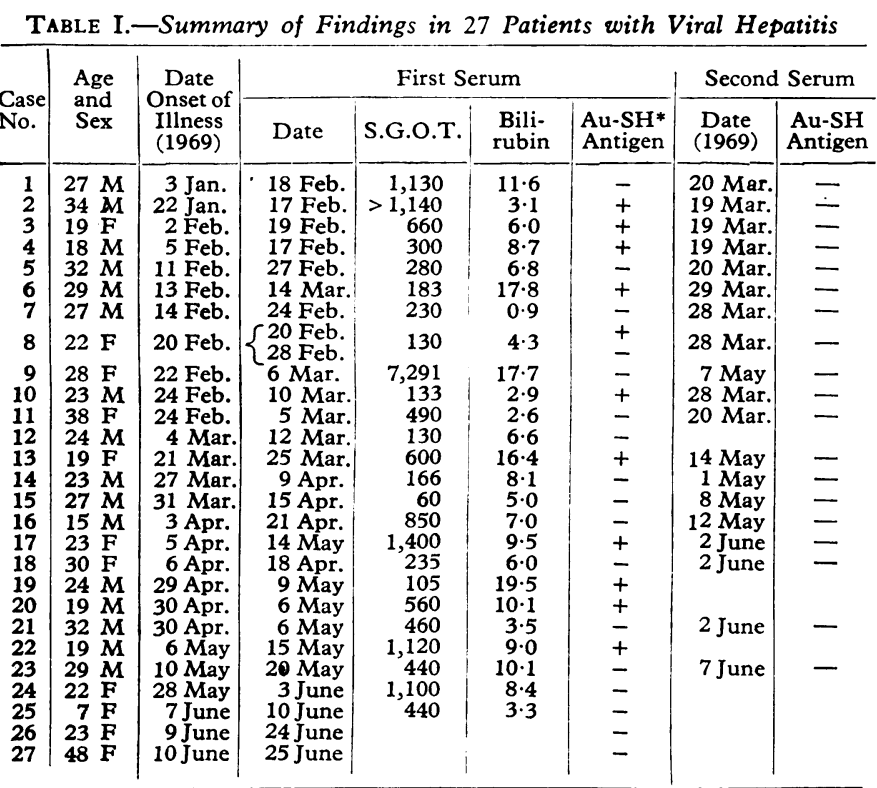

S.G.O.T. $=$ Sigma-Frankel units $/ 100 \mathrm{ml}$. Bilirubin $=$ Total serum bilirubin in mg. $/ 100 \mathrm{ml}$.

TABLE II.-Comparison of Results Between Laboratories

\begin{tabular}{|c|c|c|c|c|c|c|c|}
\hline \multirow{3}{*}{ Case No. } & \multicolumn{4}{|c|}{ School of Hygiene } & \multirow{2}{*}{\multicolumn{3}{|c|}{$\frac{\text { Virus Reference Laborato ry }}{\text { Serum }}$}} \\
\hline & \multicolumn{4}{|c|}{ Serum } & & & \\
\hline & a & b & c & d & a & b & e \\
\hline $\begin{array}{c}1 \\
2 \\
3 \\
4 \\
5 \\
6 \\
7 \\
8 \\
9 \\
10 \\
11 \\
12 \\
13 \\
14 \\
15 \\
16 \\
17 \\
18 \\
19 \\
20 \\
21 \\
22 \\
23 \\
24 \\
25 \\
26 \\
27 \\
\text { Au(1) control } \\
\text { Patient T } \\
\text { control }\end{array}$ & $\begin{array}{c}- \\
++ \\
+ \pm \\
\bar{t} \\
\pm \\
\pm \\
+++ \\
\pm \\
\pm \\
= \\
+ \\
++ \\
++ \\
++ \\
+ \\
\pm \\
= \\
= \\
++\end{array}$ & $\begin{array}{c}- \\
++ \\
++ \\
\pm \\
+ \\
\pm \\
\pm \\
++ \\
\bar{t} \\
++ \\
\pm \\
= \\
++ \\
++ \\
++ \\
+ \\
++ \\
= \\
= \\
= \\
+++\end{array}$ & 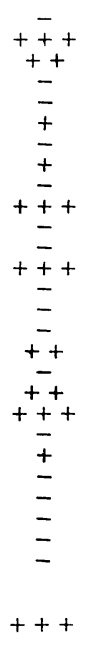 & $\begin{array}{c}\overline{+}+ \\
\pm \\
= \\
= \\
= \\
++ \\
= \\
\pm \\
= \\
\pm \\
+ \\
\pm \\
\pm \\
\pm \\
= \\
= \\
++\end{array}$ & 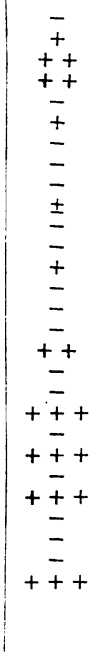 & $\begin{array}{c}- \\
++ \\
+ \\
++ \\
= \\
++ \\
= \\
= \\
= \\
\pm \\
\pm \\
= \\
\pm \\
\pm \\
+ \\
\pm \\
\pm \\
\pm \\
\pm \\
\pm \\
\overline{+}\end{array}$ & 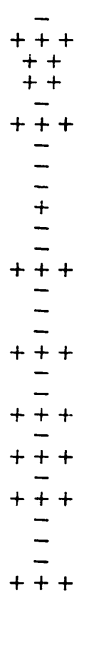 \\
\hline
\end{tabular}

The intensity of the precipitin lines was graded subjectiyely,,, \pm++++++ Absence of a detectable precipitin line is denoted by -
When the results of the two laboratories were compared (Table II) 8 of the 11 were positive on all tests, but several differences were found. Case 4 was positive at the Virus Reference Laboratory only, and Case 19 at the School of Hygiene only. We think that a difference between Cases 4 and 19 was probably due to technical factors which we are at present investigating. As the study was undertaken completely blindly, however, we feel that the correlation between the results of the two laboratories is nevertheless very striking. Serum obtained from Case 8 on the day of onset was positive at the School of Hygiene, but that obtained eight days later and tested at the Virus Reference Laboratory was negative. While this supports the suggestion (Gocke and Kavey, 1969) that earlier specimens are more likely to contain antigen no significant difference was found in this study between the proportion of positive sera collected in the first 12 days of illness, 6 out of 11 , and the proportion of positive sera collected between the 13th and 30th days, 5 out of 11 .

The lines of precipitation between the same antigen and the different antisera varied in intensity. In three instances one serum failed to detect antigen in specimens positive with the others.

\section{Comment}

The Australia-SH antigen had been found in widely scattered geographical areas (Blumberg et al., 1968), and in this series it has been present in $11(40 \%)$ out of 27 patients with viral hepatitis examined in England.

The cases were not classified as either "infectious" or "serum" hepatitis. Prince (1968) found the antigen in 11 out of 15 cases of hepatitis following blood transfusion, but he failed to find it in five patients with infectious hepatitis. Gocke and Kavey (1969), on the other hand, reported that $80 \%$ of their patients in both categories possessed the antigen in their sera. Wright, McCollum, and Klatskin (1969) found $25 \%$ of infectious hepatitis patients positive by this test.

A major reason for the wide variation in incidence of the antigen is likely to be the difference in the criteria adopted for making the clinical distinction between infectious and serum hepatitis. It is probably not due to technical factors nor to differences in the specificity of the antisera. This is supported by the close agreement in this study between the results obtained independently by the two laboratories testing the same clinical specimens under somewhat varying conditions, and using five indicator-sera. These sera, derived both from persons living in the United States and in this country, detected antigen in the sera of the same 11 persons in the present series.

In agreement with the observations of Okochi and Murakami (1968), London et al. (1969), and Gocke and Kavey (1969) the presence of the antigen in the sera of patients with viral hepatitis appears to be transient during the acute phase of the disease, since the antigen was not detected in sera collected during convalescence.

We wish to thank Professor B. S. Blumberg, Dr. C. Cameron, Dr. K. Dormandy, Professor R. W. McCollum, and Dr, A. M. Prince for the supply of "reference" antibody containing serum, and serum containing the antigen.

It is a pleasure to record the interest and help of Dr. W. d'A. Maycock, Director of the National Blood Transfusion Service.

Part of this work was carried out with the aid of a generous grant from the Medical Research Council (A. J. Z.).

\section{REFERENCES}

Blumberg, B. S., Sutnick, A. I., and London, W. T. (1968). Bulletin of the New York Academy of Medicine, 44, 1566.

Gocke, D. J., and Kavey, N. B. (1969). Lancet, 1, 1055.

Levene, C., and Blumberg, B. S. (1969). Nature, 221, 195

London, W. T., Sutnick, A. I., and Blumberg, B. S. (1969). Annals of Internal Medicine, $70,55$.

Okochi, K., and Murakami, S. (1968). Vox Sanguinis, 15, 374.

Prince, A. M. (1968). Proceedings of the National Academy of Sciences, 60,814 .

Wright, R., McCollum, R. W., and Klatskin, G. (1969). Lancet, 2, 117. 